\title{
Socio-demographic Profiles of Subjects with Co-morbid Alcohol Use Disorder and Depression in the Niger Delta Region of Nigeria
}

\author{
Chukwujekwu Chidozie Donald, ${ }^{1, *}$, Okeafor Chukwuma Ugochukwu', \\ Olose Emmanuel Omamurhomu ${ }^{2}$ \\ ${ }^{1}$ Department of Neuropsychiatry, University of Port Harcourt Teaching Hospital, Port Harcourt, Rivers State, Nigeria \\ ${ }^{2}$ Department of Psychiatry, University of Calabar, Calabar, Nigeria \\ Email address: \\ chidozie.chukwujekwu@uniport.edu.ng (C. C. Donald) \\ ${ }^{*}$ Corresponding author
}

\section{To cite this article:}

Chukwujekwu Chidozie Donald, Okeafor Chukwuma Ugochukwu, Olose Emmanuel Omamurhomu. Socio-demographic Profiles of Subjects with Co-morbid Alcohol Use Disorder and Depression in the Niger Delta Region of Nigeria. American Journal of Psychiatry and

Neuroscience. Vol. 4, No. 3, 2016, pp. 43-47. doi: 10.11648/j.ajpn.20160403.12

Received: April 30, 2016; Accepted: May 9, 2016; Published: May 17, 2016

\begin{abstract}
The study was designed to ascertain the socio-demographic profiles of patients suffering from co-morbid Alcohol Use Disorders and Depression, attending the General outpatient Clinic of the University of Port Harcourt Teaching Hospital. Consenting subjects recruited by a systematic sampling procedure between February and July 2011 were enlisted in the study. The Alcohol Use Disorders Identification Test (AUDIT) and the Beck's Depression Inventory (BDI) were administered to each. Additional information was obtained through a self-designed socio-demographic questionnaire. Fifty nine (12.6\%) of the cohort were diagnosed with Alcohol Use disorders (AUD), one hundred and thirty four (28.5\%) with major depression and twenty seven (5.7\%) with both AUD and major depression. The female and male genders were shown to be significantly associated with co-morbid depression and AUD respectively. The notion that women alcoholics are more vulnerable to drink in response to negative effect than male alcoholics may further explain the statistically significant higher prevalence of depression among females with AUD in comparison to males with the same co-morbidity. Formal education should be intensified in the developing world, and the need to protect the vulnerable segment of our population especially women cannot be overemphasized.
\end{abstract}

Keywords: Gender, Socio-demographic, Co-morbid, Alcohol, Depression

\section{Introduction}

Among individuals with Alcohol Use Disorders (AUD), data suggest gender differences in both rates of Depression $[1,2,3]$ and depressive symptoms $[2,4]$ with women showing more Depression than men. Such differences may merely reflect the higher rate of Depression observed among women in the general population. Nolen-Hoeksema [5] theorized that women's vulnerability to the toxic triangle of disordered eating problem, drinking and depression is caused by their gender tendency, compared with men, to respond to stress with ruminations which is a form of self-focused coping.
Some researchers have noted that the rates of co-morbid depression among alcohol-dependent men and women also vary by age and race although they are not as large as gender differences [6, 7]. Conner et al [8] in a meta-analysis of Depression and Substance use among individuals with Alcohol Use Disorders found that women shared higher levels of Depressive symptoms, and that whites showed higher levels of depressive symptoms than racial and ethnic minorities. Levels of depressive symptoms did not vary by age, marital status, educational attainment or employment status.

From the foregoing, a lot has been done in the developed world in the area of elucidating the relationship between Alcohol Use Disorders and Depression. However, same 
cannot be asserted in our country. Although some significant research has been undertaken in Nigeria with regard to Alcoholism in its broad sense [9, 10, 11, 12], a search of literature revealed a dearth of research in co-morbidity of Alcohol Use Disorders and Depression among general hospital out-patients. Some studies have looked at how AUD and depression affects both genders [13, 14]. Nevertheless, most of the work done on Alcohol and Alcohol related problems in Nigeria have been done in the Western part of the country and only a few in other partsincluding the Niger Delta. The aim of this study is to ascertain the sociodemographic profiles of patients suffering from co-morbid Alcohol Use Disorder and Depression in the Niger Delta Region of Nigeria. This will help identify vulnerable segments of our population that would require more attention in our war against the twin malady of Alcohol Use Disorder and DepressionIn the light of the foregoing, this study has become imperative.

\section{Materials and Methods}

This prospective cross-sectional study was conducted at the general outpatient clinic of the University of Port Harcourt Teaching Hospital (UPTH) over a six month period, from February 2011 - July 2011.

\subsection{Instruments}

For this study, the instruments employed were as follows:

1 Alcohol Use Disorders Identification Test (AUDIT)

2 Beck's Depression Inventory (BDI)

3 Composite International Diagnostic Interview (CIDI)

4 Sociodemographic protocol designed by the authors

The Alcohol Use Disorder Identification Test (AUDIT) is a self rated 10-item questionnaire with each item scored 0-4, giving a total score of 40 . Some studies have shown its validity and reliability in the detection of hazardous drinking, alcohol abuse and dependence. It has been reported that a score of 5 provides a good tradeoff between sensitivity and specificity $[15,16,17]$. It has been revalidated and used in Western Nigeria [18].

The Beck's Depression Inventory (BDI) is a 21 item self report inventory [19]. It is one of the most used instruments for screening and estimating the intensity of Depression. It has been revised in the second edition, to reflect the Diagnostic and Statistical Manual (DSM-IV) diagnostic criteria [20]. In terms of its psychometric properties, the second edition of BDI has been positively correlated with the Hamilton Depression Rating Scale (HDRS) with a Pearson Coefficient $(\delta)$ of 0.71 , showing good agreement. The test was also shown to have high test-retest reliability $(=0.93)$ and a high internal consistency $(\delta=0.91)$ [21]. Each item has four statements and the patient chooses that which applies best to their feelings over the previous two weeks. A value of 0.3 is assigned to each answer and then the total is computed to determine the severity of Depression. The scores range from 0 to $63[19,22]$. The questionnaire can be completed in 5 minutes. It has been revalidated and used in Western Nigeria and a score of 18 and above has been shown to be indicative of Depressive Disorder [23, 24].

The Composite International Diagnostic Interview (CIDI) is used for the assessment of mental disorders and to provide diagnosis according to International classification of Disease $10^{\text {th }}$ Revision (ICD-10) of the World Health Organization (1992) and the fourth edition of Diagnostic and Statistical Manual of mental disorders (DSM-IV) of the American Psychiatric Association (1994). It is particularly useful in epidemiological studies of mental disorders and can be completed in a relatively short time. The inter-rater reliability has been found to be excellent, the test-retest reliability is good and the validity has been demonstrated to be good [25]. It has been widely used in different studies within Nigeria [26, 27].

The paper and penal form of the world Mental Health CDI version 3.0 was used for this study. For the purpose of this study and due to the unavailability of the diagnostic algorithm of CIDI, diagnosis of Alcohol Used Disorders and major Depression were made by matching the symptoms generated by CIDI with the DSM-IV diagnostic criteria.

\subsection{Procedure}

The study took place in 2 phases; in the first phase, the AUDIT and BDI instruments were administered to 470 subjects. Diagnosis of major depression was made according to the DSM-IV diagnostic criteria using the Composite International Diagnostic Criteria (CIDI). One hundred and eighty five (185) subjects met the criteria for the second stage viz:- a score of 18 and above on the BDI and/or a score of 5 and above on AUDIT.

Systematic sampling technique was used to select the subjects. Every fourth eligible patient registered at the general outpatient clinic for the day was selected from the medical records register. Ballot method was used to select the first patient for the day from the eligible patients registered for a particular session. Subsequently, every fourth from the position selected by ballot was selected until the end of the clinic session. Consenting patients were recruited as described above on each clinic day until the required sample size was achieved.

Before the commencement of this study, approval of the ethical committee of the University of Port Harcourt Teaching Hospital (UPTH) was sought and informed consent obtained from the subjects to be involved in the research. The data was analyzed using the Statistical Package for Social Sciences (SPSS), version 20 at 5\% level of significance and 95\% confidence interval. Proportion or categorical parameters were analyzed with the chi-square test or 2-tailed Fisher's exact test as appropriate multivariate correlation analysis was used to establish measures of association between socio-demographic variables and Alcohol Use Disorders, Depression and co-morbidity. Continuous variables like the Beck's Depression Inventory (BDI) scores were compared by the student's t-test. 


\section{Results}

Fifty nine $(12.6 \%)$ of the subjects were diagnosed with Alcohol Use Disorders according to the DSM-IV criteria. One hundred and thirty four $(28.5 \%)$ of the subjects were diagnosed with a Major Depression Episode and twenty seven (5.7\%) were diagnosed with both Alcohol Use Disorders and Major Depression Episode.

Table 1 shows the association of the socio-demographic variables with Depression co-morbidity among the subjects with AUD. The female gender was shown to be significantly associated with co-morbid Depression. Eighty percent (80\%) of the females with AUD were also diagnosed with Depression in contrast to the $38.8 \%$ of the males with AUD that were diagnosed with Depression $\left(X^{2}=5.686, d f=1, p\right.$ value $=0.033, O R=6.32$ ). There were no other significant association of other socio-demographic variables with depression co-morbidity among the subjects with AUD.

In table 2 , among the subjects with depression, the male gender was shown to be significantly associated with comorbid AUD. It shows that $33.9 \%$ of the male depressives had co-morbid AUD compared to $10.9 \%$ of the female depressives with co-morbid AUD $\left(X^{2}=11.353 \%, d f=1, p\right.$ value $=0.001, O R=4.49 \%$ ). Also, not being a Muslim was also associated with AUD co-morbidity among the subjects with Depression. The prevalence of AUD co-morbidity was 19.2\% among the Christians. The two Traditionalist and the Eckist that had AUD were depressed but none of the Muslims with depression had AUD. This was significant $\left(X^{2}=13.473 \%, d f=2, p\right.$ value $\left.=0.001\right)$. There were no other significant associations of other socio-demographic variables with AUD co-morbidity among the subjects with Depression.

Table 1. Association of Socio-Demographic Variables with Co-Morbidity in Subjects with Alcohol Use Disorder. N=59.

\begin{tabular}{|c|c|c|c|c|c|c|}
\hline & & AUD Onlyn (\%) & $\begin{array}{l}\text { Co-morbid AUD } \\
\text { Depression n (\%) }\end{array}$ & Sub Total & $X^{2}$ & P value \\
\hline \multirow{5}{*}{ Age Group in Years } & $18-27$ & $6(54.5)$ & $5(45.5)$ & 11 & 1.232 & 0.873 \\
\hline & $28-37$ & $12(50.0)$ & $12(50.0)$ & 24 & & \\
\hline & $38-47$ & $11(61.1)$ & $7(38.9)$ & 18 & & \\
\hline & $48-57$ & $2(66.7)$ & $1(33.3)$ & 1 & & \\
\hline & $58-67$ & $1(33.3)$ & $2(66.7)$ & 3 & & \\
\hline \multirow{2}{*}{ Gender } & Male & $30(61.2)$ & $19(38.8)$ & 49 & 5.686 & $0.33 *$ \\
\hline & Female & $2(20.0)$ & $8(80.0)$ & 10 & & \\
\hline \multirow{6}{*}{ Ethnicity } & Ibo & $9(56.2)$ & $7(43.8)$ & 16 & 3.489 & 0.836 \\
\hline & Ikwerre & $7(63.6)$ & $4(36.4)$ & 11 & & \\
\hline & Ogoni & $2(40.0)$ & $3(60.0)$ & 5 & & \\
\hline & Ijaw & $4(50.0)$ & $4(50.0)$ & 8 & & \\
\hline & Other South-South ethnic groups & $8(57.1)$ & $6(42.9)$ & 14 & & \\
\hline & Others & $2(40.0)$ & $3(60.0)$ & 5 & & \\
\hline \multirow[t]{2}{*}{ Marital Status } & $\begin{array}{l}\text { Presently Unmarried** (widowed, } \\
\text { divorced, separated, and single) }\end{array}$ & $15(55.0)$ & $12(44.4)$ & 27 & 0.035 & 0.852 \\
\hline & Married & $17(53.1)$ & $15(46.9)$ & 32 & & \\
\hline \multirow{3}{*}{ Religion $* * *$} & Christianity & $32(57.1)$ & $24(42.9)$ & 56 & 3.746 & 0.000 \\
\hline & Others & $0(0.0)$ & $3(100.0)$ & 3 & & \\
\hline & (none of the Muslims had AUD) & & & & & \\
\hline \multirow{4}{*}{ Education } & Tertiary & $21(56.8)$ & $16(43.2)$ & 37 & 1.46 & 0.691 \\
\hline & Secondary & $8(50.0)$ & $8(50.0)$ & 16 & & \\
\hline & Primary & $3(60.0)$ & $2(40.0)$ & 5 & & \\
\hline & No Formal & $0(0.0)$ & $1(100.0)$ & 1 & & \\
\hline \multirow{3}{*}{ Employment } & Unemployed & $3(50.0)$ & $3(50.0)$ & 6 & 5.083 & 0.406 \\
\hline & Student & $6(46.2)$ & $7(53.8)$ & 13 & & \\
\hline & Employed & $23(57.5)$ & $17(42.5)$ & 40 & & \\
\hline \multirow{3}{*}{$\begin{array}{l}\text { Monthly Income in } \\
\text { Naira }\end{array}$} & $\leq 30.000$ & $21(50.0)$ & $21(50.0)$ & 42 & 1.972 & 0.741 \\
\hline & $<30.00-100.00$ & $8(61.5)$ & $5(38.5)$ & 13 & & \\
\hline & $<100,000$ & $3(75.0)$ & $1(25.0)$ & 4 & & \\
\hline
\end{tabular}

* Significant; **Includes widowed, divorced, separated and single; ***None of the Muslims had Alcohol Use Disorder. 
Table 2. Association of socio-demographic variables with co-morbidity in subjects with depression. $N=134$.

\begin{tabular}{|c|c|c|c|c|c|c|}
\hline & & Depression Onlyn (\%) & $\begin{array}{l}\text { Co-morbid AUD, } \\
\text { Depression n (\%) }\end{array}$ & Sub Total & $X^{2}$ & P value \\
\hline \multirow{5}{*}{ Age Group in Years } & $18-27$ & $42(89.4)$ & $5(10.6)$ & 47 & 5.852 & 0.210 \\
\hline & $28-37$ & $30(71.4)$ & $12(28.6)$ & 42 & & \\
\hline & $38-47$ & $21(75.0)$ & $7(25.0)$ & 28 & & \\
\hline & $48-57$ & $9(90.0)$ & $1(10.0)$ & 10 & & \\
\hline & $58-67$ & $5(71.4)$ & $2(28.6)$ & 7 & & \\
\hline \multirow{2}{*}{ Gender } & Male & $37(66.1)$ & $19(33.9)$ & 56 & 11.353 & $0.001^{*}$ \\
\hline & Female & $70(89.7)$ & $8(10.9)$ & 78 & & \\
\hline \multirow{6}{*}{ Ethnicity } & Ibo & $39(84.8)$ & $7(15.2)$ & 46 & 8.438 & 0.296 \\
\hline & Ikwerre & $24(85.7)$ & $4(14.1)$ & 28 & & \\
\hline & Ogoni & $9(75.0)$ & $3(25.0)$ & 12 & & \\
\hline & Ijaw & $4(50.0)$ & $4(50.0)$ & 8 & & \\
\hline & Other South-South ethnic groups & $25(80.6)$ & $6(19.4)$ & 31 & & \\
\hline & Others & $6(66.7)$ & $3(33.3)$ & 9 & & \\
\hline \multirow{3}{*}{ Religion } & Christianity & $101(80.8)$ & $24(19.2)$ & 125 & 13.473 & $0.001 *$ \\
\hline & Islam & $6(100.0)$ & $0(0.0)$ & 6 & & \\
\hline & Others & $0(0.0)$ & $3(100.0)$ & 3 & & \\
\hline \multirow{2}{*}{ Marital Status } & $\begin{array}{l}\text { Presently Unmarried** (widowed, } \\
\text { divorced, separated, and single) }\end{array}$ & $60(83.3)$ & $12(16.7)$ & 72 & 1.173 & 0.279 \\
\hline & Married & $47(75.8)$ & $15(24.2)$ & 62 & & \\
\hline \multirow{4}{*}{ Education } & No Formal & $21(56.8)$ & $16(43.2)$ & 37 & 1.46 & 0.691 \\
\hline & Primary & $8(50.0)$ & $8(50.0)$ & 16 & & \\
\hline & Secondary & $3(60.0)$ & $2(40.0)$ & 5 & & \\
\hline & Tertiary & $0(0.0)$ & $1(100.0)$ & 1 & & \\
\hline \multirow{3}{*}{ Employment } & Unemployed & $13(81.2)$ & $3(18.8)$ & 16 & 8.816 & 0.117 \\
\hline & Student & $25(78.1)$ & $7(21.9)$ & 32 & & \\
\hline & Employed & $69(70.4)$ & $29(29.6)$ & 98 & & \\
\hline \multirow{3}{*}{$\begin{array}{l}\text { Monthly Income in } \\
\text { Naira }\end{array}$} & $\leq 30.000$ & $87(86.1)$ & $14(13.9)$ & 101 & 1.979 & 0.740 \\
\hline & $<30.00-100,000$ & $15(75.0)$ & $5(38.5)$ & 20 & & \\
\hline & $<100,000$ & $5(83.3)$ & $1(16.7)$ & 6 & & \\
\hline
\end{tabular}

* Significant; **Includes widowed, divorced, separated and single.

\section{Discussion}

In consonance with the outcome of other studies [4], there was a greater likelihood of Depression among the subjects that were diagnosed with AUD than those that were not suffering from AUD. The higher proportion of males with AUD corroborates the finding in mental health literature that women drink less alcohol than men and have fewer alcoholrelated problems than men [13]. Some have also argued that the main reason women do not drink more than men is that the social sanctions against drinking are greater for women than for men [13]. Related to the social "sanctions" theory is the theory that alcohol consumption is part of the male gender role and not the female's [14]. Additionally, it may be more difficult for women than it is for men to disclose shameful behaviour connected to alcohol abuse because of the greater social stigma attached to substance abuse for them.

The higher prevalence of AUD among the respondents from the South-South ethnic groups in comparison to that of other ethnic groups not indigenized in the south-south region of Nigeria was not statistically significant. This might have been due to the adaptation of persons from other ethnic groups to the environment in which they found themselves.
Similar to other findings $[15,20,21]$, there were no statistically significant relationship between AUD and other socio-demographic factors like marital status, employment and income. It is noteworthy to mention that none of the Muslim subjects was diagnosed with AUD. This is not surprising since alcohol is forbidden in Islam, and the tendency to conceal its use among the faithful for fear of sanctions is equally high.

Although the prevalence of Depression was slightly higher among females reflecting the higher prevalence of depression in females in the general community, the gender difference only becomes statistically significant among the subjects with AUD. In other words, there was a statistically significant higher prevalence of depression among females with AUD in comparison to males with AUD [15, 16, 17]. This conforms to other studies. This could suggest that females with AUD may be more likely to have Depression than males with AUD. Rubonis et al (1994) also demonstrated that women alcoholics are more vulnerable, to drink in response to negative effect than male alcoholics. Some researchers have also argued that women's drinking is more often the result of underlying depression than men's drinking $[16,17]$.

There was a lower prevalence of depression among the 
married than those that had no spouse (including the single, widowed, divorced/separated). This conforms to the findings of other workers portraying the protective effect of marriage in depression $[18,19]$.

In line with other studies [18, 19], the less educated and lower income earners were over represented among the depressed. A possible explanation is that education affords the people the opportunity to understand their socio-cultural environment in a better perspective. Therefore, they tend to adapt better to the potential stressors in their environment. Furthermore, low educational status is also linked to low socio-economic status. Also confirming the findings of Glazamarian and James (1995), there was no statistically significant association between age and Depression in this study.

\section{Conclusion}

There is greater likelihood of Depression among subjects that were diagnosed with AUD than those that were not suffering from AUD, especially among females. Depression was found higher in subjects of lower socio-economic status. The findings from this study underscores the need to encourage formal education at all levels in the undeveloped world, as well as encourage policies and measures that would enhance the socio-economic well being of the vulnerable segment of humanity especially women.

\section{Limitation}

This study was conducted using clinically derived sample which obviously limits generalization to the general population.

\section{References}

[1] Tamerin JS, Weiner S, Mendelson JH. Alcoholic's expectancies and recall of experiences during intoxication. Am JPsychiatry 1970; 1261: 1697-1704.

[2] Brady KT, Grace DE, Dustan L, Randall C. Gender difference in substance use disorders. Am J Psychiatry 1993; 150: 1707 1711 .

[3] Compton WM., Conway KP, Stinsin FS, Grant BF. Changes in the prevalence of major depression and co-morbid substance use disorders in the United States between 19911992 and 2001-2002. Am J Psychiatry 2006; 163: 2141-2147.

[4] Swendsen JD, Merikangas KR. The co-morbidity of depression and substance use disorders. Clin Psychol Rev 2000; 20: 173-189.

[5] Nolen-Hoeksema S. Gender differences in risk factors of consequences for alcohol use and problems. Clin Psychol Rev 2004; 24, 981-1010.

[6] Shuckit M A, Tipp J E, Bergman M, Reich W, Hesselbrook U $\mathrm{M}$, Smith T L. Comparison of induced and independent major depressive disorders in 2,945 alcoholics. Am J Psychiatry1997; 154: 948-57.

[7] Hesselbrook MN, Meyer RE, Keene JJ. Psychopathology in hospitalized alcoholics. Arc of Gen Psychiatry 1985; 42: 1050-1055.

[8] Conner, R. K., Pinquert M., Gamble SA. Meta-analysis of depression and substance use among individuals with Alcohol Use Disorders. Jour Subst Abuse Treat 2009; 37: 127-137.

[9] Ohaeri JU, Oduyela SO, Odejide OA, Dipe TM, Ikwuagwu PU, Zamani A. The history of drinking behaviour of the Nigerian students' palm wine drinkers club. Drugs Edu Prev Policy 1996; 3: 171-183.

[10] Obot IS. The measurement of drinking patterns and alcohol problems in Nig Jour Subst Abuse 2000; 12: 169-181.

[11] Stanley PC, Nwaneri DU, Bob-Yellow E. Prevalence of Alcohol Withdrawal Syndrome in Port Harcourt, Niger Delta Region of Nigeria. January 1999- December 2003. Neurol Asia 2005; 10: 53-57.

[12] Adewuya AO. Prevalence of major depressive disorder in Nigeria College Students with Alcohol - related problems. Gen Hosp Psychiatry 2006; 28: 169-173.

[13] Blume SB. Sexuality and Stigma. The alcohol woman. Alcohol health and research world: special issue. Alcohol and Sexuality 1991; 15: 139-146.

[14] Landerine H, Bardwell S, Dean T. (1988). Gender expectations for alcohol use. A study of the significance of the masculine role. Sex Roles 1988; 19: 703-712.

[15] Helzer J, Pryzbeck T. The co-occurrence of alcoholism with other psychiatric disorders in the general population and its impact on treatment. Journ Alc Studies 1988; 49: 219-224.

[16] Rubonis AV, Colby SM, Monti PM, Rohsenow DJ. Alcohol reactivity and mood induction in male and female alcoholics. Journ Stud Alcohol 1994: 55, 487-494.

[17] Kessler RC, Crum RM, Warner LA, Nelson CB, Schulenberg J, Anthony JC. Lifetime co-occurrence of DSM-III-R, Psychiatric Disorders in the United States. Results from the National Comorbidity Survey. Arch Gen Psychiatry 1997; 51: 8-19.

[18] Cho MJ, Nam JJ, Suh GH. Prevalence of Symptoms of Depression in Nationwide Sample of Korean adults. Psych Research 1998; 81: 341-352.

[19] Gazamararian AJ, James S A, Lepkowski JM. Depression in Black and White Women. The role of marriage and socioeconomic status. American journal of psychology 1995; 5: 453-463.

[20] Schuckit MA, Smith TL, Kalmijin K. Relationships among independent major depressive, alcohol use and other substance use and related problems over 30 years in 397 families. Journ Stud Alc Drugs 2013; 74: 271-279.

[21] Magidson JF, Saal W, Nel A, Remmert E, Kagee A. Relationship between depressive symptoms, alcohol use and anti-retroviral therapy adherence among HIV- infectad, clinic attending patients in South Africa. J Health Psychol Feb.15 20161359105316628743. 